\title{
Patterns of gas and liquid reflux during transient lower oesophageal sphincter relaxation: a study using intraluminal electrical impedance
}

\author{
D Sifrim, J Silny, R H Holloway, J J Janssens
}

\begin{abstract}
Background-Belching has been proposed as a major mechanism underlying acid gastro-oesophageal reflux in normal subjects. However, the presence of oesophageal gas has not been measured directly but only inferred from manometry. Aims-To investigate, using intraluminal electrical impedance, the patterns of gas and liquid reflux during transient lower oesophageal sphincter (LOS) relaxations, the main mechanism of acid reflux in normal subjects.

Methods-Impedance changes associated with the passage of gas were studied in vitro, and in vivo in cats. Oesophageal manometry, pH, and intraluminal electrical impedance measurements were performed in 11 normal subjects after a meal. Results-Gas reflux caused a sudden increase in impedance that propagated rapidly to the proximal oesophagus whereas liquid reflux induced a retrogressively propagated fall in impedance. Impedance showed gas or liquid reflux during most (102/141) transient LOS relaxations. When acid reflux occurred, impedance showed evidence of intraoesophageal retrograde flow of liquid in the majority $(78 \%)$ of events. Evidence of gas retroflow was found in almost half $(47 \%)$ of acid reflux episodes. When present together, however, liquid preceded gas on $44 \%$ of occasions. Overall, gas reflux occurred as the initial event in only $25 \%$ of acid reflux episodes. Conclusions-These findings suggest that in upright normal subjects, although belching can precipitate acid reflux, most acid reflux occurs as a primary event. (Gut 1999;44:47-54)
\end{abstract}

Keywords: belching; gastro-oesophageal reflux disease; oesophageal manometry; intraluminal electrical impedance; lower oesophageal sphincter

Department of Gastroenterology, Royal Adelaide Hospital, Adelaide, South Australia R H Holloway

Correspondence to: Dr D Sifrim, Faculty of Medicine KU Leuven, Lab G-I Physiopathology, O\&N Gasthuisberg, 7th floor, Herestraat 49, 3000 Leuven, Belgium.

Accepted for publication 22 July 1998 be a variant of the belch reflex. ${ }^{9}$ Recently, observations on manometric patterns of pressure associated with reflux have also been interpreted as indicating that the majority of reflux episodes are associated with belching. ${ }^{10}{ }^{11}$

The air/liquid composition of the refluxate and its subsequent intraoesophageal retrograde flow, however, have been poorly characterised, largely because of difficulty in imaging accurately the presence and movement of air in the oesophagus. In humans, direct observation of gastro-oesophageal liquid reflux has been possible using fluoroscopy, ${ }^{12}$ scintigraphy, ${ }^{13}{ }^{14}$ and ultrasonography. ${ }^{15-17}$ Prolonged oesophageal $\mathrm{pH}$ recordings using multiple $\mathrm{pH}$ sensors ${ }^{18}$ and/or fibreoptic sensors for bilirubin detection $^{19}{ }^{20}$ have provided information about the spatiotemporal and chemical characteristics of the liquid refluxate. Oesophageal air can be visualised directly during fluoroscopy ${ }^{21}$ but this is impractical for long term recordings of spontaneous events. Several investigators have also used the abrupt rise in oesophageal pressure typically associated with reflux of gas, the "common cavity", as indirect evidence of gas reflux. $^{8}{ }^{922}$

Because spontaneous transient LOS relaxations in humans are relatively infrequent and their timing unpredictable, assessment of associated patterns of oesophageal flow requires prolonged monitoring. The measurement of intraluminal electrical impedance has been introduced recently to investigate the characteristics of bolus transport in both the oesophagus $^{23-26}$ and duodenum. ${ }^{27} 28$ This technique is based on changes in electrical impedance between two electrodes during passage of a bolus, and allows for prolonged monitoring and detection of liquid and/or air movements within the oesophageal lumen. Recent studies in infants combining $\mathrm{pH}$ and impedance measurements have validated this method for detection of acid as well as non-acid gastrooesophageal reflux episodes. ${ }^{29}$ Although the presence of air in the oesophagus induces typical impedance changes, ${ }^{24}$ this technique has not been used, thus far, to monitor gastrooesophageal reflux of air in man.

The aims of this study, therefore, were firstly to validate the use of intraluminal electrical impedance to assess gastro-oesophageal reflux of gas; and secondly, to characterise the patterns of retrograde flow of gas and liquids

Abbreviations used in this paper: LOS, lower oesophageal sphincter; TLOSR, transient lower oesophageal sphincter relaxation; cc, common cavity 


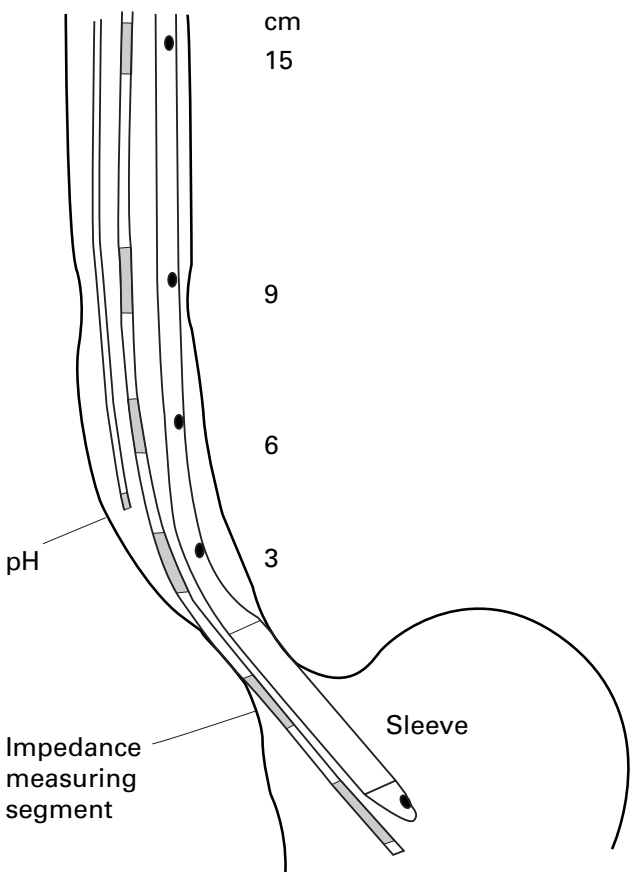

Figure 1 Schematic representation of recording assemblies in the normal subjects. The hatched areas on the impedance assembly indicate $2 \mathrm{~cm}$ recording segments between pairs of electrodes.

during transient LOS relaxations in healthy subjects.

\section{Methods}

INTRALUMINAL ELECTRICAL IMPEDANCE

Intraluminal electrical impedance was recorded with a series of cylindrical electrodes, each $4 \mathrm{~mm}$ in axial length, spaced at $2 \mathrm{~cm}$ intervals and incorporated into a $2.3 \mathrm{~mm}$ diameter polyvinyl assembly (Prototype developed by Professor Jiri Silny at the Helmholtz Institute for Biomedical Engineering, Unit of Technology, Aachen, Germany). Each pair of electrodes formed a measuring segment, $2 \mathrm{~cm}$ in length, corresponding to one recording channel. Two assemblies were used: one had eight recording segments over a distance of 16 $\mathrm{cm}$ for in vitro and in vivo validation studies; the other, for studies in humans, had eight measuring segments from which six were selected over a distance of $24 \mathrm{~cm}$ (fig 1). Each pair of electrodes was connected to an impedance transducer which delivered a measuring current of less than $6 \mathrm{~mA}$ at a frequency of $1 \mathrm{kHz}$. Impedance was recorded continuously, digitised at $100 \mathrm{~Hz}$, and stored in a computer for subsequent analysis.

OESOPHAGEAL MANOMETRY AND $\mathrm{pH}$

Oesophageal manometry was performed with a multilumen manometric assembly. A sleeve sensor recorded LOS pressure. A side hole at the distal margin of the sleeve recorded gastric pressure; oesophageal body pressure was recorded at four sites by side holes 3, 6, 9, and 15 $\mathrm{cm}$ proximal to the sleeve (fig 1). Each lumen was perfused with distilled water at $0.5 \mathrm{ml} / \mathrm{min}$ by a pneumohydraulic capillary perfusion pump. Swallowing was monitored with a separate water filled non-perfused catheter posi- tioned in the hypopharynx above the upper oesophageal sphincter. Pressures were sensed by external pressure transducers (pvb, Medizintechnik $\mathrm{GmbH}$, Germany). Oesophageal $\mathrm{pH}$ was recorded by a glass $\mathrm{pH}$ electrode with combined reference electrode (Ingold 440-M3, Switzerland) which was attached to the manometric assembly $3 \mathrm{~cm}$ above the proximal margin of the sleeve sensor. The $\mathrm{pH}$ electrode was calibrated in buffers of $\mathrm{pH} 1$ and 7 before and after each study. Pressure and $\mathrm{pH}$ signals were amplified, digitised at $16 \mathrm{~Hz}$ using a Synectics PC Polygraf 16HR (Synectics, Stockholm, Sweden), and stored in a computer for subsequent analysis.

\section{VALIDATION STUDIES}

In vitro model

The characteristics of the impedance changes associated with gas flow were investigated in an experimental in vitro model by the injection of small volumes $(0.1-5 \mathrm{ml})$ of air (three times each volume) into the base of a water filled column (10 $\mathrm{mm}$ diameter; $20 \mathrm{~cm}$ height) into which was placed an eight channel impedance assembly. Impedance was recorded as the bubble of air that was created rose up the water filled column.

\section{In vivo model}

Impedance changes associated with oesophageal retrograde flow of gas or liquid were also investigated in vivo in four cats lightly anaesthetised with ketamine chloride (10-15 mg/kg intramuscularly for induction and $10 \mathrm{mg} / \mathrm{kg}$ every 30-45 minutes for maintenance). An impedance assembly incorporating eight measuring segments over $16 \mathrm{~cm}$ was placed in the distal oesophagus under fluoroscopic control. The stomach was loaded with air (160-240 ml) or a solution of $10 \%$ dextrose, pH 2, with $5 \%$ Gastrograffin (80-240 ml), and concurrent oesophageal videofluoroscopy and impedance were recorded until gastro-oesophageal reflux occurred. A digital time signal was simultaneously displayed on the video and impedance recordings for use in data analysis and synchronisation. Animal studies were carried out in accordance with the Guiding Principles in the Care and Use of Animals and were approved by the Animal Care Committee of the Catholic University of Leuven.

\section{Studies in human subjects}

Oesophageal manometry, intraluminal impedance, and $\mathrm{pH}$ were measured concurrently in 11 healthy volunteer subjects (five men, six women; mean age 20 years, range 18-24). All subjects were free of oesophageal symptoms and were not taking any medication. The study was approved by the University Hospital Ethics Committee and written informed consent was obtained from all subjects.

Subjects were studied after an overnight fast of at least 10 hours. The manometric assembly and $\mathrm{pH}$ electrode were passed through the mouth (under topical pharyngeal anaesthesia) and positioned manometrically with the sleeve sensor straddling the LOS. The impedance assembly was also passed orally but positioned 
under fluoroscopic control such that the most distal measuring segment (segment 1) was at the level of the gastric side hole, segment 2 was in the LOS at the level of the distal end of the metallic stiffener in the sleeve sensor, and segments 3, 4, 5, and 6 were 3, 6, 9, and $15 \mathrm{~cm}$ respectively above the sleeve sensor (fig 1). After placement of the assemblies, the subjects remained in a sitting position for one hour to obtain a baseline recording. The subjects then ate a semiliquid meal prepared from vanilla pudding, egg, cream, and dextrose $(350 \mathrm{ml}$, $3.30 \mathrm{MJ}, 47 \%$ fat). After the meal, the subjects remained sitting and recordings were made for another two hours.

\section{DATA ANALYSIS}

Validation studies

The impedance changes evoked by air flow (in vitro and in vivo models) or liquid oesophageal retrograde flow (in vivo) were analysed for the location and number of detecting measuring segments at which retrograde flow was detected, the amplitude of impedance changes, and the propagation velocity.

\section{Studies in human subjects}

The digitised manometric, $\mathrm{pH}$, and impedance signals were imported into an IBM compatible computer and displayed on a single screen. The impedance recordings were synchronised with the manometric and $\mathrm{pH}$ recordings using a dedicated software program (Review, A Andrioli, KU Leuven).

The LOS pressure recording was analysed for the occurrence of transient LOS relaxations. ${ }^{30}$ These were classified as either eventful, if accompanied by reflux as evidenced by a drop in $\mathrm{pH}$ or a common cavity (see below), or uneventful if no such features were present. The oesophageal body pressure recordings were analysed for the occurrence of common cavities that were defined as abrupt and sustained rises of 5 to $10 \mathrm{mmHg}$ in basal oesophageal pressure in at least the two lower oesophageal body manometric recording sites. ${ }^{9}$

The $\mathrm{pH}$ recording was analysed for reflux episodes. All abrupt falls in $\mathrm{pH}$ (within a time frame of eight seconds) of at least $1 \mathrm{pH}$ unit were identified and counted. Falls in $\mathrm{pH}$ were classified as traditional if $\mathrm{pH}$ fell below 4 for at least 15 seconds. All other $\mathrm{pH}$ drops were classified as non-traditional: either they fell across $\mathrm{pH} 4$ for less than 15 seconds or they occurred when basal $\mathrm{pH}$ was already below 4 .

The impedance recording was analysed on the basis of previous studies in the human oesophagus $^{23} 2429$ and duodenum, ${ }^{27}$ and also our validation studies (see results). A liquid bolus passing an oesophageal impedance measuring segment generates a typical pattern of impedance change. In the resting state, oesophageal impedance values range between 1.5 and $5 \mathrm{k} \Omega$ whereas those in the stomach are of the order of $0.5 \mathrm{k} \Omega$. The arrival of the bolus front is indicated by a drop in impedance. Lumen occlusion at the tail of the bolus by the oncoming peristaltic contraction slowly restores impedance values to their resting levels (fig 2). Intraoesophageal liquid flow provokes a sequential drop in impedance at multiple impedance measuring segments allowing the direction of flow to be determined. With the subjects sitting, retrograde intraoesophageal

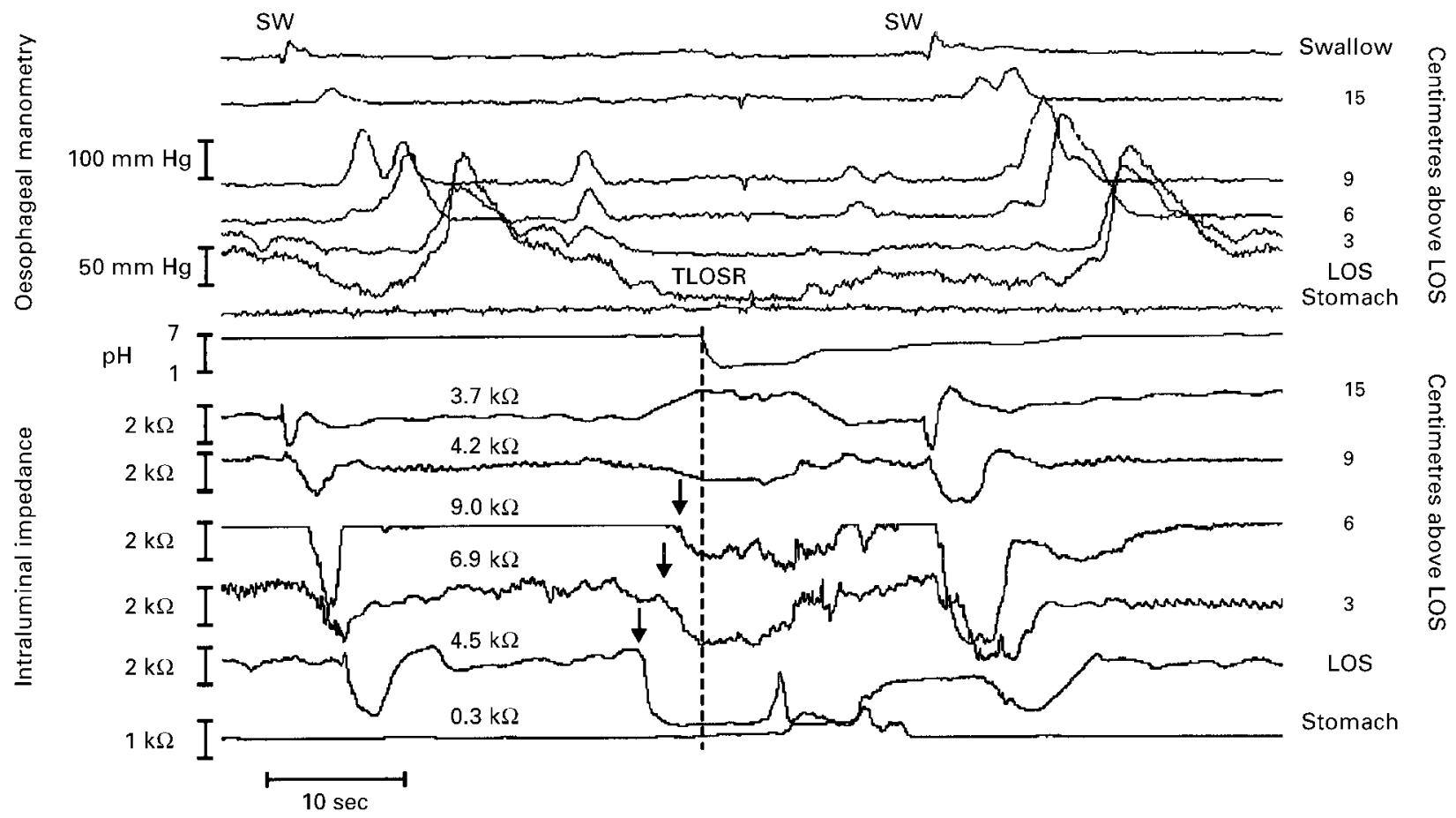

Figure 2 Tracing of concurrent manometry, $p H$, and intraluminal impedance. Primary peristalsis (sw) is associated with a sequential drop in impedance that propagates in an antegrade fashion. A transient LOS relaxation (TLOSR) occurs after the first primary peristaltic sequence and is associated with liquid acid reflux as evidenced by a fall in $\mathrm{pH}$ (indicated by the vertical dashed line), and a retrogressively propagated drop in impedance (arrows) that precedes the $\mathrm{pH}$ drop. 

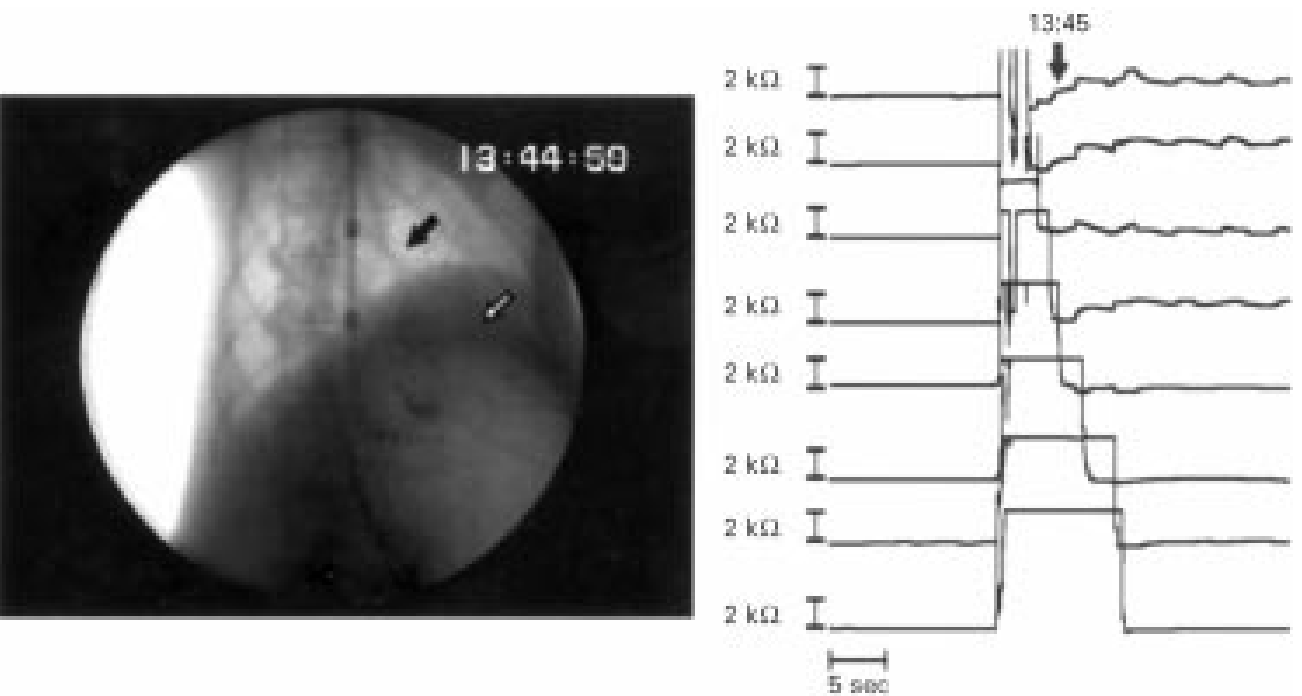

Figure 3 Radiographic appearance (left) and oesophageal impedance changes (right) associated with gas reflux in the cat. The $x$ ray shows an oesophageal common cavity with gas evident in both the stomach (white arrow) and oesophagus (black arrow). This reflux episode was associated with an abrupt, almost simultaneous increase in impedance at all measuring segments.

flow of liquid was defined as a drop in impedance to $\leqslant 40 \%$ of the baseline values starting distally at segment 2 (at the level of the LOS) and propagating to at least the next more proximal measuring segments.

The electrical conductivity of air is nearly zero. Injection of an air bolus into the proximal oesophagus or gastro-oesophageal reflux of air observed fluoroscopically in the validation studies (see results) initiated an abrupt, almost simultaneous increase in impedance in several measuring segments (fig 3). Spontaneous swallowing was occasionally associated with an antegressively propagated increase in impedance, probably due to swallowed air. ${ }^{31}$ Therefore, reflux of gas was defined as a rapid (3 $\mathrm{k} \Omega / \mathrm{sec}$ ) increase in impedance, occurring simultaneously in at least two oesophageal measuring segments, in the absence of swallowing.

STATISTICAL ANALYSIS

The relation between the presence of a common cavity phenomenon or intraoesophageal gas with the proximal extent of oesophageal retrograde flow of liquids was analysed using the Fisher exact test followed by a Categorical Data Modelling for main effects (SAS/STAT 6.04, Cary, North Carolina, USA). Data on changes in impedance are reported in text as median (range).

\section{Results}

VALIDATION STUDIES

Impedance changes induced by air flow

In vitro model-The upward movement of an air bubble within a water filled column was detected as a rapid increase in impedance (3 $\mathrm{k} \Omega / \mathrm{sec}$ ) in all measuring segments. The amplitude of impedance changes depended on the volume of the air bubble (fig 4). Upward movement of tiny air bubbles of $0.1 \mathrm{ml}$ provoked a sequential increase in impedance of $0.98 \mathrm{k} \Omega(0.73-1.15 \mathrm{k} \Omega$ ), slowly progressing from distal to proximal measuring segments.
Air volumes from 2 to $5 \mathrm{ml}$ provoked increases in impedance of 5-6 $\mathrm{k} \Omega$ above the basal recording $(1.5 \mathrm{k} \Omega$ ) almost simultaneously at several measuring segments.

In vivo model-Oesophageal retrograde flow of air was concurrently recorded with videofluoroscopy and impedance during 14 air gastro-oesophageal reflux events in two cats (fig 3). Fluoroscopy performed as the stomach was being distended showed that air suddenly escaped into the oesophagus. The air escaping from the stomach appeared to distend the oesophageal lumen. Shortly thereafter, a peristaltic wave stripping the oesophagus returned the refluxed gas into the stomach. Before reflux of air, the median intraoesophageal impedance baseline value was $2.24 \mathrm{k} \Omega(1.42-3.85 \mathrm{k} \Omega)$. The sudden entrance of air into the oesophagus was recorded as a rapid increase in impedance in all 14 events. The impedance increase occurred simultaneously in all eight measuring segments in seven $(50 \%)$ air reflux events, and in four to seven measuring segments in the other seven events. The amplitude of impedance changes was not uniform among measuring segments; impedance reached the limit of recording of $10 \mathrm{k} \Omega$ in $72 \%$ of cases, was $5-10 \mathrm{k} \Omega$ in $13 \%$ of cases, and was below $5 \mathrm{k} \Omega$ in $12 \%$ of cases. After a median of six seconds (range 3-180 seconds) impedance values returned progressively in an aboral

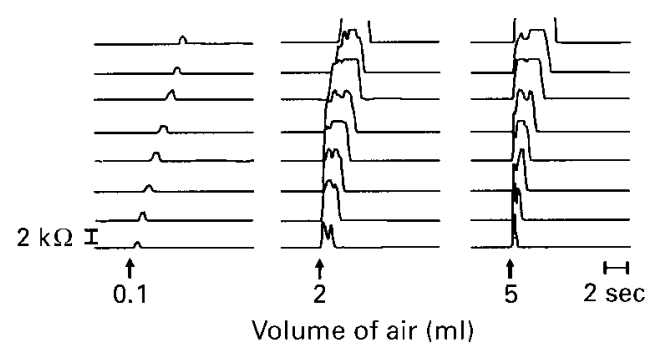

Figure 4 Impedance changes associated with the upward movement of a gas bubble in a column of water. 

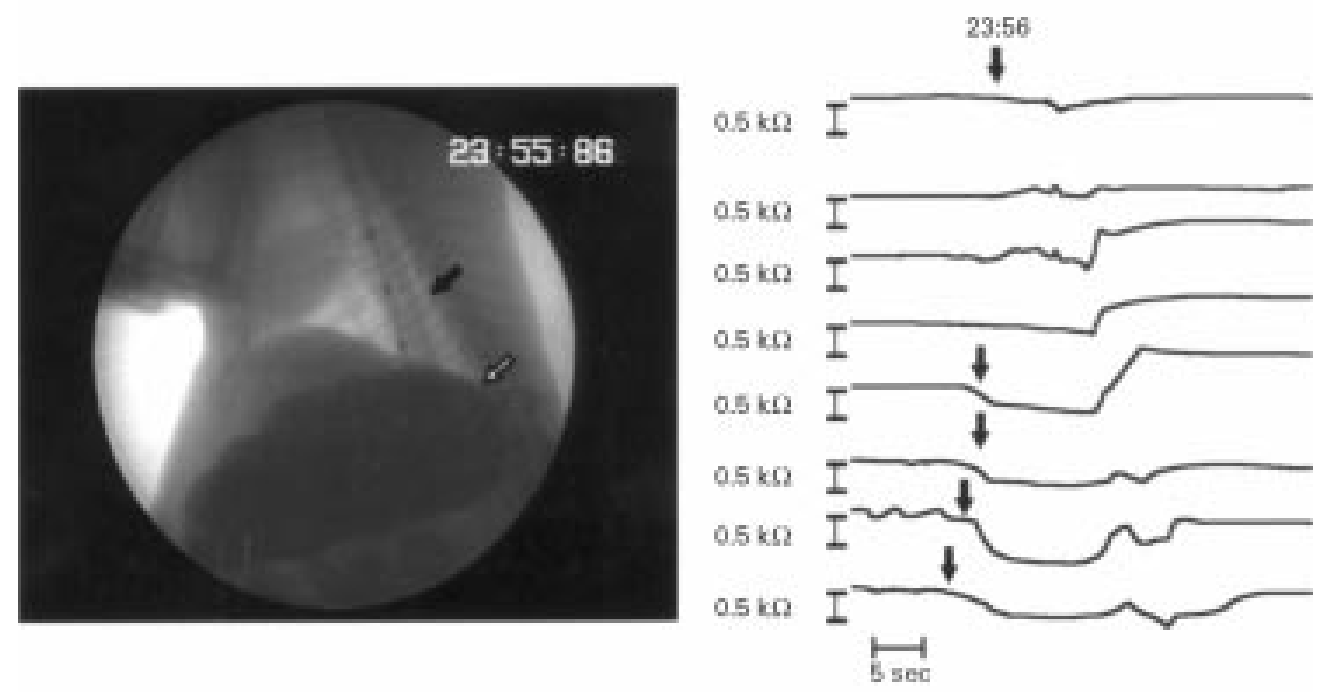

Figure 5 Radiographic appearance (left) and oesophageal impedance changes (right) associated with liquid reflux in a cat. The $x$ ray shows liquid in both the stomach (white arrow) and oesophagus (black arrow). The gastro-oesophageal reflux episode was associated with a retrogressively propagated drop in impedance (arrows).

direction to baseline values simultaneously with the peristaltic stripping wave observed under fluoroscopy.

Impedance changes induced by oesophageal retrograde flow of liquid in vivo

Oesophageal retrograde flow of liquid was recorded concurrently with videofluoroscopy and impedance during six gastro-oesophageal reflux events in two cats (fig 5). Fluoroscopy, performed as the stomach was being filled and distended with a radio-opaque acidic solution, showed that liquid suddenly escaped into the oesophagus. Thereafter, a peristaltic wave stripping the oesophagus returned the refluxed liquid into the stomach. Gastro-oesophageal reflux of liquid was recorded as an orad sequential drop in impedance starting at the most distal measuring segment (at the level of the LOS). In five of the six events a drop in impedance was observed up to $8 \mathrm{~cm}$ above the LOS. Before reflux, the median intraoesophageal impedance baseline value was $1.2 \mathrm{k} \Omega$ $(0.8-2.2 \mathrm{k} \Omega)$. The median drop in impedance provoked by liquid reflux was $0.63 \mathrm{k} \Omega$ (0.37-1.64 k $\Omega$ ) (median $46.5 \%$; range 39.5$71 \%$ of baseline values). The drop in impedance occurred in an orad sequence at a median of $3.15 \mathrm{~cm} / \mathrm{sec}$ (range $0.49-6.12 \mathrm{~cm} / \mathrm{sec}$ ). Impedance values returned progressively to baseline values simultaneously with the peristaltic stripping wave observed under fluoroscopy.

STUDIES IN HUMANS

A total of 141 transient LOS relaxations was scored with a median of 11 per subject (range 3-22). During the 141 transient LOS relaxations, impedance measurements recorded evidence of reflux, either liquid or gas, on 102 (72\%) occasions (fig 6).

Impedance changes associated with acid reflux Impedance evidence of retrograde flow of liquid was present in the majority $(40 / 51,78 \%)$ of transient LOS relaxations associated with acid reflux (fig 2), and occurred in 36 of the 45 relaxations associated with both a $\mathrm{pH}$ drop and a common cavity, and four of the six relaxations associated only with a $\mathrm{pH}$ drop. In the majority $(34 / 40,85 \%)$ of transient LOS relaxations refluxate was detected $\geqslant 6 \mathrm{~cm}$ above the LOS; in the remaining six relaxations liquid refluxate was restricted to $<6 \mathrm{~cm}$ above the LOS.

Impedance evidence of retrograde flow of gas was present with almost half $(24 / 51,47 \%)$ of the transient LOS relaxations associated with acid reflux. Gas was equally prevalent when the $\mathrm{pH}$ drop was accompanied by a common cavity (22/45 events) as when there was only a $\mathrm{pH}$ drop ( $2 / 6$ events). Evidence of gas was consistently seen in the proximal oesophagus causing an abrupt increase in impedance to a level above $10 \mathrm{k} \Omega$. In the distal $6 \mathrm{~cm}$ of the oesophagus, impedance changes tended to be of lower amplitude and shorter duration than that in the proximal oesophagus, sometimes
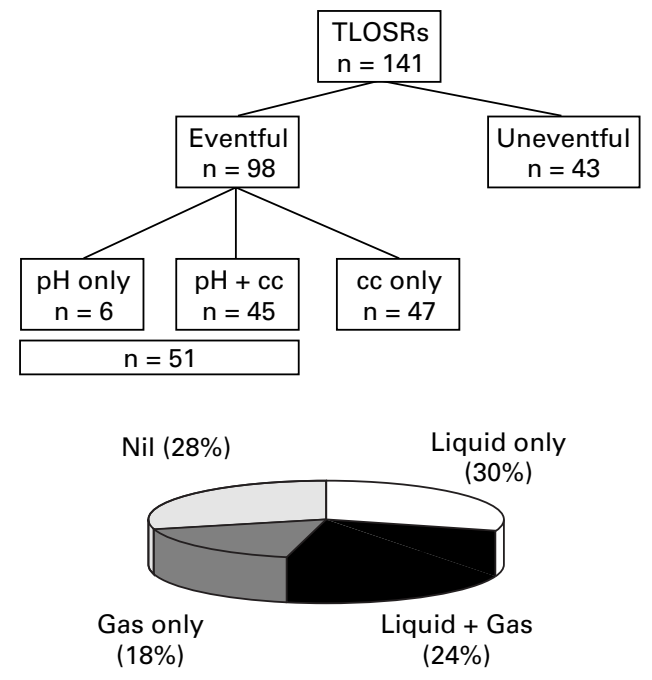

Figure 6 Patterns of reflux during transient LOS relaxations based on $\mathrm{pH}$ and manometric criteria. The pie chart shows the proportion of different impedance patterns observed during transient LOS relaxations. TLOSR, transient LOS relaxation. cc, common cavity. 
amounting to only a small spike of around $0.5-1 \mathrm{k} \Omega$. In a small proportion $(29 \%)$ of reflux episodes, although gas was seen in the proximal
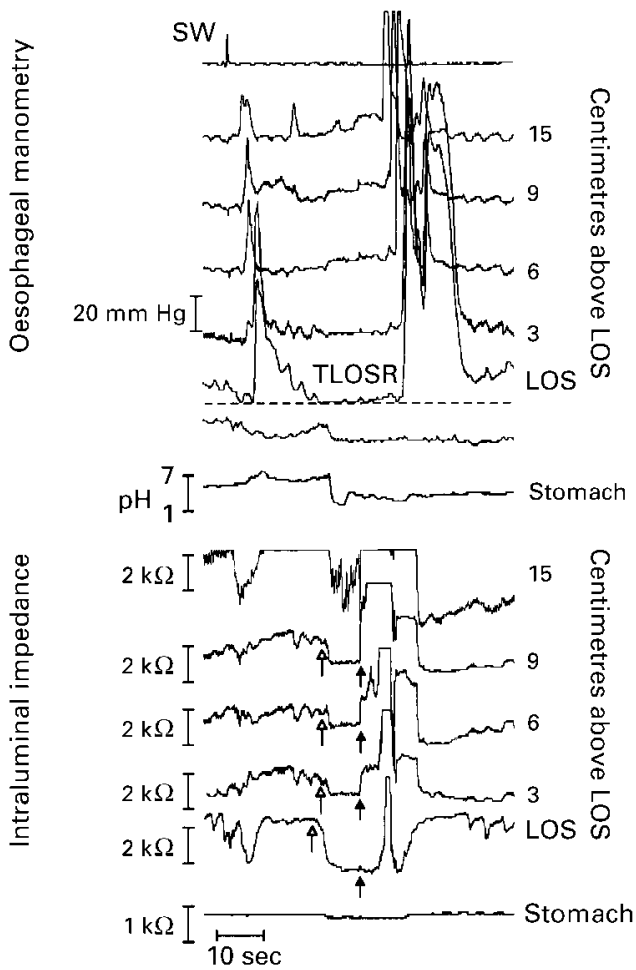

Figure 7 Tracing of concurrent manometry, $p H$, and intraluminal impedance. A transient lower oesophageal sphincter relaxation (TLOSR) is associated with a common cavity and acid reflux as evidenced by a $\mathrm{pH}$ drop. The impedance tracing shows an initial drop (open arrows) consistent with liquid reflux followed by a large, abrupt, and almost simultaneous increase (closed arrows), indicative of gas reflux. oesophagus, no impedance changes were evident in the distal oesophagus.

When both gas and liquid were present, the impedance drop (indicative of liquid) preceded the impedance increase (indicative of gas) on $44 \%(8 / 18)$ of occasions (fig 7). In such circumstances, the $\mathrm{pH}$ drop was traditional on seven occasions. In contrast, when the gas preceded the liquid, the $\mathrm{pH}$ drop was nontraditional on six of 10 occasions.

Intraoesophageal gas was detected in $44 \%$ (34/77) of transient LOS relaxations with liquid reflux. The presence of gas, however, did not affect the intraoesophageal distribution of the liquid. When gas was present, liquid was detected $\geqslant 9 \mathrm{~cm}$ above LOS on $50 \%$ of occasions compared with $56 \%$ of occasions when gas was absent.

\section{Impedance changes associated with oesophageal} common cavities

A total of 92 common cavities was scored. Impedance evidence of either gas or liquid reflux was present in 87 (95\%): gas only in 24, liquids and gas in 31 , and liquid only in 37 . A common cavity was seen with virtually all (90/ 92) episodes of gas reflux.

Liquid refluxate tended to extend more proximally in the presence of a common cavity. Intraluminal impedance showed evidence of retrograde flow of liquids in 77 transient LOS relaxations, 65 of which were associated with a common cavity. When a common cavity was present, liquid was detected $\geqslant 9 \mathrm{~cm}$ above the LOS on $56 \%$ of occasions compared with $33 \%$ of occasions when a common cavity was absent $(\mathrm{p}<0.05)$.
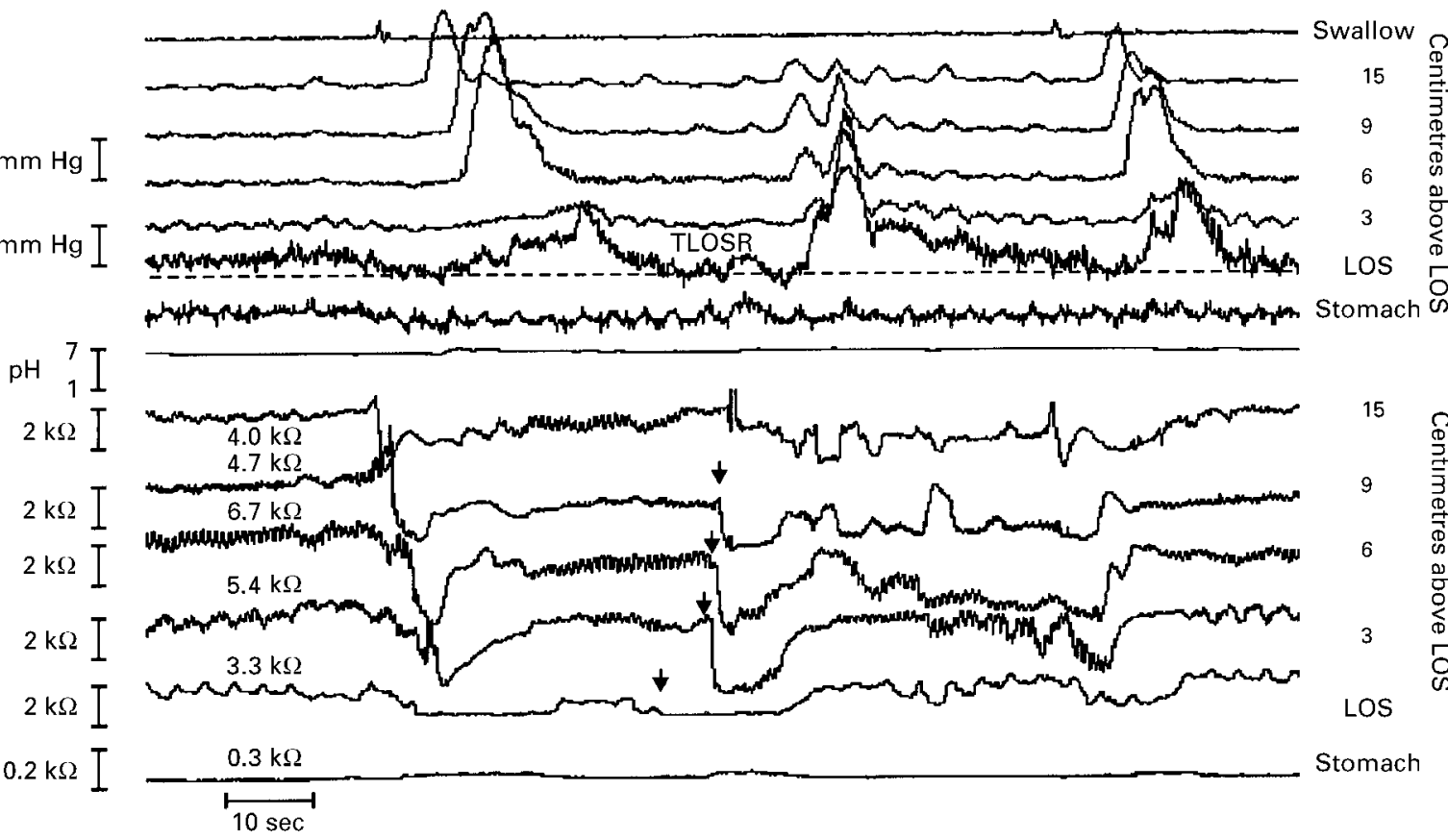

Figure 8 Tracing of concurrent manometry, $p H$, and intraluminal impedance during an uneventful (absence of common cavity and $p H$ change) transient lower oesophageal sphincter relaxation (TLOSR). The horizontal dashed line indicates the level of intragastric pressure. The TLOSR is associated with a retrogressively propagated drop in impedance (arrows) caused by non-acidic liquid reflux. 
Uneventful transient LOS relaxations

Forty three transient LOS relaxations were not associated with either a $\mathrm{pH}$ drop or a common cavity. Intraluminal impedance evidence of retrograde flow of liquid was present with eight $(19 \%)$ of these events (fig 8), and only three uneventful transient LOS relaxations had evidence of retrograde flow of gas.

Impedance changes localised to the LOS segment A drop in impedance that was confined to the distal measuring segment (LOS) occurred with 22 transient LOS relaxations, five of which were also associated with a $\mathrm{pH}$ change. However, because impedance evidence of liquid reflux was not seen in the oesophagus, these events were not scored as liquid reflux events.

\section{Discussion}

Understanding of patterns of gas and liquid reflux during transient LOS relaxations may yield important insights into the normal control of liquid reflux during transient LOS relaxations and, more importantly, into potentially disordered control of liquid reflux in patients with reflux disease. To date, however, inferences about the composition of the refluxate with respect to liquid and gas have been largely speculative in the absence of a sensitive and practical means of detecting and monitoring intraoesophageal gas. In this study we have evaluated the use of intraluminal impedance to detect reflux of gas and liquid, and applied the technique to the investigation of patterns of gas and liquid reflux during transient LOS relaxations. The major findings were that in normal subjects in the upright position: (a) the majority of transient LOS relaxations were accompanied by reflux, either of liquid, gas, or both; (b) half of the acid reflux episodes were associated with reflux of gas; and (c) when acid reflux was associated with reflux of gas, reflux of liquid preceded the gas in $44 \%$ of instances.

Although the impedance values of gas and liquid are widely different, it was important to identify and define the patterns of impedance change associated with the reflux of gas and liquids as there are no published reports of impedance changes associated with spontaneous gas reflux. We used in vitro and in vivo models in which episodes of gas flow and gas and liquid reflux could be confirmed by visual or radiological means. Such observations established that movement of gas is associated with a propagated abrupt increase in impedance that contrasts notably with the drop in impedance associated with the flow of liquids. Our models do not mimic naturally occurring postprandial reflux. Nevertheless, they do allow patterns of impedance change associated with isolated movement of gas or liquid to be identified. Specific measurement of the volume of gas vented into the oesophagus during reflux has not been reported; however, radiological and manometric studies suggest that, during belching, the volume of gas is sufficient to distend the entire oesophagus. ${ }^{81}$ Based on these patterns of impedance change, therefore, we believe that it is valid to interpret the impedance changes observed in humans in terms of whether or not the refluxate was predominantly gas - that is, was the reflux event a belch, or was it predominantly liquid reflux. The sensitivity of the technique for detecting small amounts of gas in a large volume of liquid, small amounts of liquid in a large volume of gas, or a fine mix of liquid and gas, has not been determined, and without another more sensitive marker of gas reflux as a gold standard such assessment is not possible.

As in earlier studies ${ }^{29}$ reflux of liquid was associated with a retrogressively propagated drop in impedance that was clearly distinguishable not only from the abrupt increase associated with gas reflux but also from the antegressively propagated drop in impedance associated with peristalsis. In humans, the pattern of impedance increase associated with upright reflux of gas varied along the oesophagus. In the proximal oesophagus, the impedance change matched that seen in the cat and the rise was usually prolonged, suggesting that the gas was trapped. In the distal 3 to $6 \mathrm{~cm}$ of the oesophagus, however, the impedance increase was generally of lower amplitude and of briefer duration. In one third of instances, usually associated with concurrent reflux of liquid, impedance evidence of gas was seen only in the proximal two thirds of the esophagus. The reasons for this are not clear. Possibilities include: anatomical differences between the distal and proximal oesophagus; presence of liquid in the distal oesophagus that may have obscured the impedance increase; or that the gas bolus may have moved too rapidly to be captured at the acquisition rate used in this study. A higher acquisition rate would help to address this last issue. Although such events represented only a small proportion of the total number, they support the usefulness of monitoring impedance in the proximal oesophagus in order to maximise the detection of gas reflux. Even so, it is possible that small amounts of gas, insufficient to accumulate to any extent in the proximal oesophagus, might still be missed. The importance of small quantities of gas to the issue of whether or not reflux is a consequence of belching, however, is not clear.

It has been suggested that belching accounts for up to $70 \%$ of acid reflux episodes in normal subjects. ${ }^{10}$ Our findings partly support this concept as we detected gas reflux during $47 \%$ of transient LOS relaxations associated with acid reflux. However, careful analysis of the impedance changes revealed that in about half of these events, an initial drop in impedance occurred before the abrupt increase. This sequence suggests that liquid refluxed before the gas and was not a consequence of initial gas reflux. Furthermore, on such occasions the liquid was detected in the proximal half of the oesophagus, suggesting that the volume of liquid was substantial and not just a small leakage of liquid before predominantly gas reflux. Overall, gas reflux occurred as the initial event with only $25 \%$ of acid reflux episodes. Therefore, our findings suggest that in normal subjects, although belching is an important 
process leading to acid reflux, most acid reflux occurs as a primary event. The previous conclusions were based on the assumption that common cavities were a reliable marker of gas reflux. ${ }^{10}$ While this may be the case when the stomach is in the fasted state and is distended with a large volume of gas, ${ }^{89}$ our findings show that this is not the case in the postprandial state as we found impedance evidence of gas in only $60 \%$ of common cavities.

Previous studies have shown that acid reflux occurs with about $35 \%$ of transient LOS relaxations in normal subjects. ${ }^{2-43233}$ We observed similar findings, with $36 \%$ of transient LOS relaxations being associated with acid reflux. In the present study, however, we detected impedance evidence of liquid reflux in $72 \%$ of transient LOS relaxations. Detection of liquid reflux in the absence of $\mathrm{pH}$ change was largely accounted for by restriction of the refluxate to below the level of the $\mathrm{pH}$ electrode. The remaining episodes can potentially be explained by reflux of relatively neutral gastric contents early in the postprandial period. ${ }^{29}$ Virtually all acid ( $\mathrm{pH}$ positive) reflux events were associated with impedance evidence of liquid reflux.

A small number of transient LOS relaxations were associated with drops in impedance localised to measuring segments within the LOS. The significance of these is unclear. It is possible that the impedance drops represent upward movement of liquid into but not through the LOS. However, such drops also occur during swallow induced LOS relaxation and during oesophageal balloon distension (unpublished observations). Because impedance values in the stomach are much lower than those in the LOS or oesophagus, an alternative explanation is that these localised impedance drops are due to LOS relaxation itself or to movement of the measuring segment into the gastric fundus as a result of oesophageal shortening.

In summary we have evaluated and used intraluminal impedance for the measurement of gas and liquid reflux. The findings from this study challenge the popularly held belief that upright reflux of acid, especially in normal subjects, is the result primarily of gas reflux during belching. Further studies are needed in patients with reflux disease in order to determine whether patterns of gas and liquid reflux differ from those in normal subjects, and to assess the impact on these patterns on factors such as hiatus hernia or antireflux surgery.

This work was supported by grants of the FWO and of the "Geconcerteerde Onderzoeksactie" of the University of Leuven. Dr Holloway was supported by a Fellowship from the University of Leuven.

1 Dent J, Dodds WJ, Friedman RH, et al. Mechanism of gas-

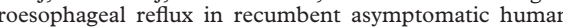
subjects. F Clin Invest 1980;65:256-67.

2 Mittal RK, McCallum RW. Characteristics of transient lower esophageal sphincter relaxation in humans. $A m \mathcal{F}$ Physiol 1987;252:G636-41.

3 Schoeman MN, Tippett MD, Akkermans LMA, et al. Mechanisms of gastroesophageal reflux in ambulant healthy human subjects. Gastroenterology 1995;108:83-91.

4 Dodds WJ, Dent J, Hogan WJ, et al. Mechanisms of gastroesophageal reflux in patients with reflux esophagitis. N Engl f Med 1982;307:1547-52.

5 Dent J, Holloway RH, Toouli J, et al. Mechanisms of lower oesophageal sphincter incompetence in patients with
symptomatic gastro-oesophageal reflux. Gut 1988;29: symptom $1020-8$.
6 Mittal RK, McCallum RW. Characteristics and frequency of transient relaxations of the lower esophageal sphincter in patients with reflux esophagitis. Gastroenterology 1988;95: 593-9.

7 Penagini R, Schoeman MN, Dent J, et al. Motor events underlying gastro-esophageal reflux in ambulant patients with reflux oesophagitis. Neurogastroenterol Motil 1996;8: 131-41.

8 Kahrilas PJ, Dodds WJ, Dent J, et al. Upper esophageal sphincter function during belching. Gastroenterology 1987; 91:133-40.

9 Wyman JB, Dent J, Heddle R, et al. Control of belching by the lower oesophageal sphincter. Gut 1990;31:639-46.

10 Barham C P, Gotley DC, Mills A, et al. Pressure events surrounding oesophageal acid reflux episodes and acid clearance in ambulant healthy volunteers. Gut 1993;34: $444-9$.

11 Barham C P, Gotley DC, Mills A, et al. Precipitating causes of acid reflux episodes in ambulant patients with gastrooesophageal reflux disease. Gut 1995;36:505-10.

12 Ott DJ. Radiology of esophageal function and gastroesophageal reflux disease. In: Scarpignato C, Galmiche JP, eds. Functional evaluation in esophageal disease. Frontiers in Functional evaluation in esophageal disease. Frontiers in 70 .

13 Shay SS, Eggli D, Johnson LF. Simultaneous esophageal pH monitoring and scintigraphy during the postprandial period in patients with severe reflux esophagitis. Dig Dis Sci 1991;36:558-64

14 Washington N, Moss HA, Washington C, et al. Non-invasive detection of gastro-oesophageal reflux using an ambulatory system. Gut 1993;34:1482-6.

15 Wright LL, Baker KR, Meny RG. Ultrasound demonstration of gastroesophageal reflux. $\mathcal{F}$ Ultrasound Med 1988;7: $471-5$.

16 Liu J, Mittal RK. Correlation between pressures, $\mathrm{pH}$ and ultrasound images during transient lower esophageal sphincter relaxation [abstract]. Neurogastroenterol Motil 1995; 7:270.

17 Hirsch W, Kedar R, Preiss U. Color doppler in the diagnosis of the gastroesophageal reflux in children: comparison with $\mathrm{pH}$ measurements and $\mathrm{B}$ mode ultrasound. Pediatr Radiol 1996;26:232-5.

18 Weusten BL, Akkermans LM, vanBerge Henegouwen GP, et al. Spatiotemporal characteristics of physiological gastroesophageal reflux. Am f Physiol 1994;266:G357-62.

19 Stein HJ, Kraemer SJ, Feussner H, et al. Quantifying intestino-esophageal reflux with a fiberoptic bilirubin detection probe. $Z$ Gastroenterol 1994;32:247-51.

20 Vaezi MF, Richter JE. Synergism of acid and duodenogastroesophageal reflux in complicated Barrett's esophagus. Surgery 1995,117:699-704.

21 McNally E, Kelly J, Ingelfinger F. Mechanism of belching: effect of gastric distension with air. Gastroenterology 1964;46:254-9.

22 Butterfield DG, Struthers JE, Showalter JP. A test of gastroesophageal sphincter competence. The common cavity test. Dig Dis 1972;17:415-21

23 Silny J. Intraluminal multiple electrical impedance procedure for measurement of gastrointestinal motility. $\mathcal{F}$ Gastrointest Motil 1991;3:151-62.

24 Silny J, Knigge KP, Fass J, et al. Verification of the intraluminal multiple electrical impedance measurement for the recording of gastrointestinal motility. $\mathcal{f}$ Gastrointest Motil 1993;5:107-22

25 Fass J, Silny J, Braun J, et al. Measuring esophageal motility with a new intraluminal impedance device. First clinical results in reflux patients. Scand F Gastroenterol 1994;29: 693-702.

26 Frieling T, Hermann S, Kuhlbusch R, et al. Comparison between intraluminal electric impedance measurement and manometry in the human oesophagus. Neurogastroenterol Motil 1996;8:45-50.

27 Nguyen HN, Silny J, Wüller S, et al. Chyme transport patterns in human duodenum, determined by multiple intraluminal impedancometry. Am f Physiol 1995;268: G700-8.

28 Nguyen HN, Silny J, Wüller S, et al. Postprandial duodenal chyme transport in healthy volunteers and patients with diabetic gastroparesis [abstract]. Neurogastroenterol Motil 1995;7:277.

29 Skopnik H, Silny J, Heiber O, et al. Gastroesophageal reflux in infants: evaluation of a new intraluminal impedance technique. F Pediatr Gastroenterol Nutr 1996;23:591-8.

30 Holloway RH, Penagini R, Ireland AC. Criteria for objective definition of transient lower esophageal sphincter relaxation. Am 7 Physiol 1995;268:G128-33.

31 Pouderoux P, Ergun GA, Lin S, et al. Esophageal bolus transit imaged by ultrafast computerized tomography. Gastroenterology 1996;110:1422-8.

32 Holloway RH, Dent J. Pathophysiology of gastroesophageal reflux. Lower esophageal sphincter dysfunction in gastroesophageal reflux disease. Gastroenterol Clin North Am 1990;19:517-35.

33 Sifrim DA, Janssens J, Vantrappen G. Transient lower esophageal sphincter relaxations and esophageal body muscular contractile response in normal humans. Gastroenterology 1996;110:659-68. 